\title{
ASSESSMENT OF EFFICIENCY OF „LANGUAGE THROUGH SPORT“METHOD ON FOREIGN LANGUAGE’ ACQUISITION
}

\author{
Eleonora Mileva, Vesela Slavova, \\ Nely Yankova \& Valentin Panayotov \\ National Sports Academy „Vassil Levski”, Sofia, Bulgaria
}

\begin{abstract}
The present study has been aimed at the assessment of efficiency of "Language through sport" method on foreign language' acquisition. The contingent of the study has been a total of 43 students at "Sport" faculty who have been distributed equally in experimental $(n=20)$ and control $(n=23)$ groups.

Methods of comparative analysis have been applied in two ways: the English language' acquisition of specific terminology by task-level achievements and the final marks of the language test.

It has been found a higher increase of students' learning achievements in the experimental group on the four tasks of the language test and some increase of the control group' performance, however, which has been smaller than that of the experimental group' students. The assessment of "Language through Sport" method on foreign language' acquisition has proved its efficiency as an educational model. All learning objectives have been achieved. It has been proved that the diversity and interactivity of the experimental method have stimulated the interest of all participants in more efficient foreign language learning.
\end{abstract}

Key words: students, weightlifting, power lifting, English, learning

\section{INTRODUCTION}

Foreign language' acquisition is a key competence, which is especially important for personal and professional realization of future sports professionals (Brambarova, 1986; Stefanova, 2007). Integrating a foreign language into sports training process is one of the most powerful strategy that higher sport pedagogical education is required to accomplish. In this regard, the acquisition and the use of standardized international terms of specific sports (in English) included in sports practice preparation have been determined by the need of new and specific models for effective learning. The efficiency of this new method of teaching could improve students' knowledge and skills for successful and continuous learning of a foreign language, for self-direction and management of their professional careers. The implementation of new and contemporary model of training for students of the National Sports Academy "Vassil Levski", combining foreign language learning and sports training is considered to improve the existing educational practice in both areas. This new educational model, which is an innovation in the training methodology, would lead to improvement of lasting knowledge and mastering key skills.
The experimental teaching method "Language through Sport" has not been applied in students' training at NSA "Vassil Levski", but there is some experience in the application of foreign language teaching in a training environment. For more than 15 years, the Foreign Languages Section and the Winter Spots Department at NSA "Vassil Levski" have conducted similar experience for their students in the perspective of mastering sport terminology in English. Specialized ski and snowboard textbooks have been developed and published. Unfortunately, however, neither the students' readiness for this type of learning nor its results or its efficiency were examined. Therefore, our desire was to continue, deepen and enrich our scientific knowledge by exploring the previously unexplored approach to foreign language learning "Learning by doing" in sports pedagogical practice. We strongly believe that an individualized interactive approach to the implementation of language teaching is crucial for successful language classes. For this reason, it is of particular importance to evaluate the results of the experimental educational approach in comparison with the traditional one applied in academic practice - an entirely new study on the subject that will enrich the knowledge in this field of sports 
science.

\begin{abstract}
Aim and objectives of the study
The present study has been aimed at the assessment of efficiency of "Language through sport" method on foreign language' acquisition. It was necessary to validate and assess this new and innovative teaching approach by students' academic achievements for improving educational practice of learning foreign language in sports setting.
\end{abstract}

\section{METHODOLOGY}

In order to achieve this goal, a specific language-teaching curriculum was elaborated, as well as a specialized methodology for sport training including English-language terms of weightlifting and power lifting on topics. Using the experience of some of the participants in the project mainly during blended training of foreign (program „Erasmus + “) and Bulgarian students in the technique of competitive exercises in power lifting and weightlifting, were developed and applied during these classes 10 practical study modules, including previously elaborated thematic units in English.

The contingent of the study has been 43 students at "Sport" faculty who have been distributed equally in experimental $(\mathrm{n}=20)$ and control $(\mathrm{n}=23)$ groups. Methods of comparative analysis have been applied in two ways: the English language' acquisition of specific terminology by task-level achievements and the final marks of the language test.

At the beginning of the pedagogical experiment, participants' language skills were identified by applying complex assessment (written tests and oral examination). Written didactic tests were conducted at the beginning and at the end of the experimental training to assess the current level of English language proficiency of the students, and a system for assessing theoretical knowledge in the sport specialty was applied. The training was held in two stages according to the experimental study curriculum prepared in advance. The previously elaborated system for assessing the theoretical and applied knowledge of the participants, including tests for assessing their language level on the topics studied, was applied on a monthly basis, monitoring their success in terms of both experimental and traditional methods.

There have been also video recordings of training sessions in order to provide a DVD disc that is the pedagogical complement of training methodology. With the aim of studying the impact of applied methodology of language training through sports, and in particular to determine the effectiveness of the experimental training conducted, the learning achievements of the participating students were analyzed.

\section{RESULTS}

The comparative analysis was carried out in two ways: students' learning achievements measured by both written language tests and oral examinations at the beginning and the end of the experimental training. The didactic language tests used in the experiment were designed specifically for the purposes of the study to determine the level of language proficiency and skills at the beginning of the experiment, as well as the acquisition of language knowledge and skills at the end of the experiment.

The test had lasted 2 academic classes and consists of 4 parts, the total number of points to achieve being 100, distributed as follows:

Part I Listening (Questions 1-10). Duration 10 min. Result: 10 points (1 point for correct answer, 0.5 point for incomplete answer, 0 points for wrong answer). This part is about listening to a record of sports topics lasting 2-3 minutes.

Source: (Olympic Weightlifting: A Complete Guide for Athletes \& Coaches)

The task is to test students ability to understand and extract specific information from the field of sports when listening to a native speaker of the language. This assignment includes 10 sentences with missing information that students need to complete after hearing the recording. Each correct answer carries 1 point. Students are allowed to hear the recording twice and have 2 minutes between hearings.

Part II Reading comprehension (questions 1130). Duration 20 min. Result: 20 points (1 point for correct answer, 0 points for wrong answer). Source: The text is selected from specialized sports sources (Takano, 2012).

Questions are 20 in number, each marked with 1 point. The purpose is testing the students' ability to apply their foreign language grammar skills in reading and comprehending texts related to sports. Students are required to demonstrate text-reviewing skills in order to retrieve relevant information, draw conclusions, distinguish nuances in the meaning of words and phrases, understand individual details in the text, and express opinions and facts that are indicated directly or implied in context. Volume: up to 3000 characters.

Part III Use of Language. Duration $30 \mathrm{~min}$. Score: 30 points

1. Multiple Choice Questions (questions 31 - 44). 
The questions are 15 sentences with missed words or phrases and 4 possible answers, one of which is correct. Each correct answer is marked by 1 point and the wrong 0 points. Purpose: Students are required to demonstrate proficiency in basic lexical knowledge of a foreign language for weightlifting and power lifting. Some of the sentences test knowledge of word combinations and terms that are characteristic of everyday speech and sports terminology.

2. Text Building (questions 45-60). The task is to fill in 15 missing words/phrases in the text, with 4 possible answers for each of them. Students must choose the right answer. Each correct answer is marked by 1 point and the wrong one 0 points. Source: The text is chosen from popular science publications in the field of specific sports: weight lifting and power lifting (Raynolds, 2016, Strudvent, 2016).

The Aim Students should demonstrate their ability to understand a text and use their lexical and grammatical knowledge to choose the correct answer. The focus of the assignment is on specific sports terms studied at NSA "Vassil Levski," as well as the correct choice of verb tenses. Volume: 2000 characters Part IV Speaking. Duration 10 min. Result: 40 points
This section includes guidance questions (20) on the part of the teacher to check the extent to which the student is able to give detailed information about himself, his/her interests, his/her specialty, more or less freely to express an opinion. The student is asked to comment on a caption, a statement made, a short excerpt (paragraph) of an article, and more.

The purpose of test task is to check the correctness of the pronunciation (5 points), the proper use of appropriate vocabulary (5 points), mastering the simpler and more complex grammatical forms (5 points), the proper structuring of the sentences (5 points), the adequate response questions and skills to talk freely (10 points), to support or reject the interlocutors' statements (10 points). The didactic language test conducted at the beginning of the pedagogical experiment showed a similar level of language proficiency in the experimental and control groups. Table 1 shows the experimental group $(\mathrm{n}=40)$ achievements and Table 2 - the control group $(n=43)$ achievements that were used for descriptive analysis of the language test results. They allow comparisons of students' performance in experimental and control groups by numerical grades at the beginning and end of the experiment.

Table 1. Test's results obtained in experimental group

\begin{tabular}{|l|l|l|}
\hline \multirow{2}{*}{ MARKS } & \multicolumn{2}{c|}{ EXPERIMENTAL GROUP (n=20) } \\
\cline { 2 - 3 } & \multicolumn{1}{|c|}{ BEGINNING } & \\
\hline POOR 2 & $20 \%$ & $0 \%$ \\
\hline PASSABLE 3 & $40 \%$ & $10 \%$ \\
\hline GOOD 4 & $20 \%$ & $10 \%$ \\
\hline VERY GOOD 5 & $20 \%$ & $60 \%$ \\
\hline EXCELLENT 6 & $0 \%$ & $30 \%$ \\
\hline TOTAL & $100 \%$ & $100 \%$ \\
\hline
\end{tabular}

Table 2. Test's results obtained in control group

\begin{tabular}{|l|l|l|}
\hline \multirow{2}{*}{ MARKS } & \multicolumn{2}{c|}{ CONTROL GROUP (n=23) } \\
\cline { 2 - 3 } & \multicolumn{1}{|c|}{ BEGINNING } & \multicolumn{1}{c|}{ END } \\
\hline POOR 2 & $20 \%$ & $10 \%$ \\
\hline PASSABLE 3 & $40 \%$ & $15 \%$ \\
\hline GOOD 4 & $30 \%$ & $50 \%$ \\
\hline VERY GOOD 5 & $10 \%$ & $20 \%$ \\
\hline EXCELLENT 6 & $0 \%$ & $5 \%$ \\
\hline TOTAL & $100 \%$ & $100 \%$ \\
\hline
\end{tabular}

\section{DISCUSSION}

The analysis of the results showed that the students of both experimental and control groups had similar level of language competence at the beginning of the pedagogical experiment. These results were the necessary condition for the reliability of the experiment. Students in the experimental group at the end of the experiment were found to have improved their marks by reducing the percentage rate of the mark "Good", by missing the mark "Poor", and increasing the marks "Very Good" and "Excellent". Regarding the academic achievement of control group' students, it was evident that marks from the language test, which were found at the beginning of experiment, 
had been improved in percentage at the end of experiment. The marks "Poor" and "Passable" decreased and the mark "Good" increased. The data reported a small increase in the marks "Very Good" and "Excellent" for control group students in the final study. The analysis showed that the slight improvement in the control group students' achievements proved the necessity and importance of introducing a new blended method of teaching in order to increase the efficiency and quality of both language and sport training.
The next step in evaluating the learning achievements of the didactic language test was analyzing the differences in language test results between experimental and control groups at the beginning and at the end of the pedagogical experiment. The Student's t-test for dependent and independent samples was used to evaluate changes in numerical scores obtained in experimental and control groups. The changes in students' academic achievements in experimental group between the initial and final study were calculated (Figure 1).

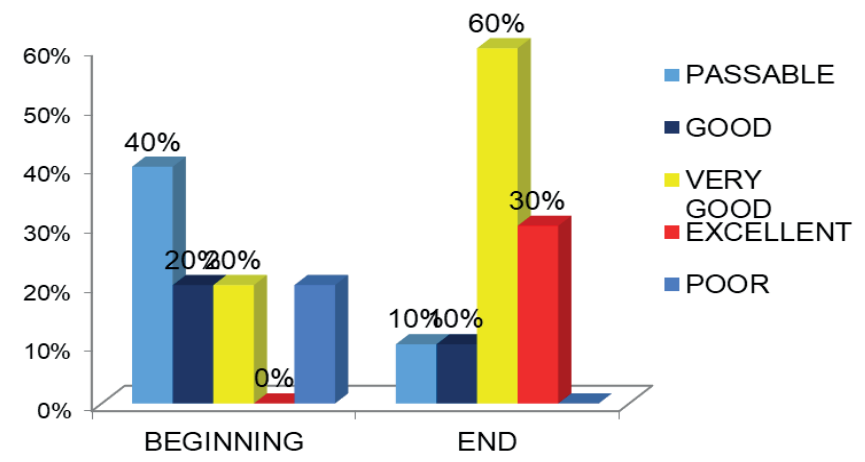

Figure 1. Analysis of students' academic achievements between initial and final study

Changes in control group students' achievements between initial and final study were also calculated (Figure 2).

The slight increase in the control group students' achievements at the end of the experiment showed some weaknesses of traditional teaching methodology whose focus was primarily on textbooks, and some lack of variability and creativity of teaching methodology, the assessment, whose criteria were not quite clear and did not account for students' progress for the particular course of study, but rather for certain fragmented knowledge, etc. Generally speaking, the front-line teaching could not create an innovative learning environment and achieve certain learning goals.

COMPARATIVE ANALYSIS OF CONTROL GROUP STUDENTS' ACHIEVEMENTS

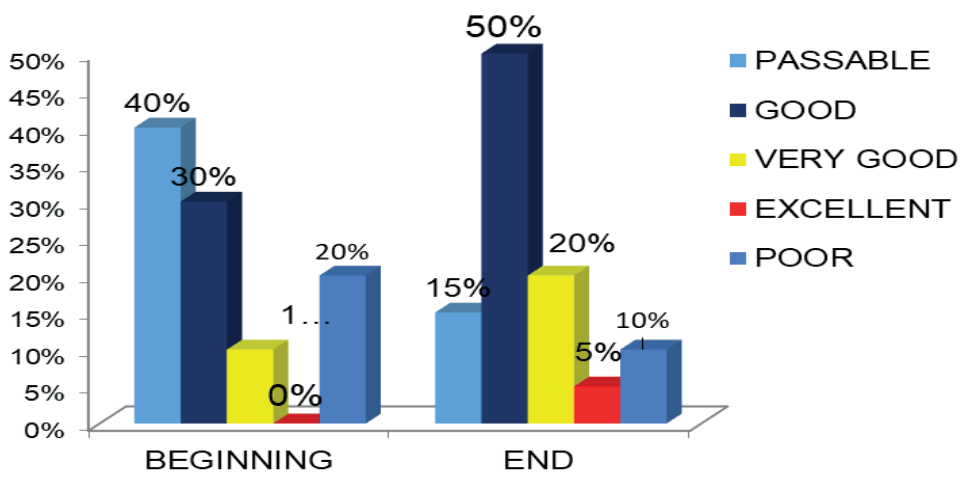

Figure 2. Analysis of the students' academic achievements between initial and final study 
The data also showed higher increases in learning achievements for all four didactic language test tasks in the experimental group than in the control group. The highest increase in learning achievements in the experimental group was in the Listening, Speaking, and Use of the Language tasks. This was probably due to the fact that the most numerous teaching activities were related to oral communication, watching and listening to audio / video learning materials, the use of specialized terminology during training sessions. Additional lexical and practical exercises were offered individually and in groups to students, both during traditional foreign language and sport sessions classes, and during blended language and sports training classes.

The comparative analysis of the academic students' achievements from in experimental and control groups gave us reason to draw the following conclusions:

1. a higher increase in the academic students' achievements in experimental group had been observed in four of five language test tasks;

2. an increase in control group students' achievements was reported, however, smaller than the growth in the achievement of the students in experimental group.

As a result of researches carried out within the project and the analyzed results, a higher efficiency of new blended methodology "Language through Sport" had been showed related to acquisition of the professional linguistic knowledge necessary for the successful realization of the specialists in weight lifting and power lifting. It had been proved that the diversity and interactivity inherent in the experimental methodology has stimulated the interest of students for faster and more complete learning of the material taught. The newly introduced "Language through Sport" methodology had been successfully implemented and the learning objectives set had been achieved, namely mastering the specialized terminology in English for weightlifting and power lifting.

\section{REFERENCES:}

Brambarova, A. (1986). Methodological aspects of selecting and teaching of learning material for specialized training, Annual methodological seminar of CFLL, FSI, Sofia, 1986, pp. 35-43.

Raynolds, M. (2016). The Ultimate Glossary of Strength and Conditioning Terms, available at:

https://www.artofmanliness.com/articles/the-ultimate-glossary-of-strength-and-conditioning-terms/ Visited in March 2018.

Stefanova, P. (2007). Foreign Language Teaching - learning, teaching and assessment, Siela, Sofia, pp. 48-53.

Studvent, G. (2016). Weightlifting terminology, available at: https://www.odu.edu/content/dam/odu/offices/ recreation-wellnesss/docs/weight-terms.pdf/ Visited in March 2018

Takano, R. (2012). Weightlifting Programming: A Winning Coach's Guide, Catalyst Athletics Inc., pp. 18-19.

$$
\begin{array}{r}
\text { Corresponding author: } \\
\text { Prof. Eleonora Mileva, DSc } \\
\text { Department „Psychology, } \\
\text { Pedagogy and Sociology“ } \\
\text { E-mail: emileva2002@yahoo.com }
\end{array}
$$$$
\text { National Sports Academy „Vassil Levski” }
$$ 